OPEN ACCESS

Edited by:

Amerigo Giudice, University Magna Graecia of

Catanzaro, Italy

Reviewed by:

Quamarul Hassan,

University of Alabama at Birmingham

United States

Fuhua Yan,

Nanjing Stomatological Hospital

(NSH), China

${ }^{*}$ Correspondence:

Derrick C. Wan

dwan@stanford.edu

Specialty section

This article was submitted to

Regenerative Dentistry,

a section of the journal

Frontiers in Dental Medicine

Received: 20 August 2020

Accepted: 19 October 2020

Published: 23 November 2020

Citation:

Tevlin R, Longaker MT and Wan DC

(2020) Skeletal Stem Cells - A

Paradigm Shift in the Field of

Craniofacial Bone Tissue Engineering.

Front. Dent. Med. 1:596706.

doi: 10.3389/fdmed.2020.596706

\section{Skeletal Stem Cells-A Paradigm Shift in the Field of Craniofacial Bone Tissue Engineering}

\author{
Ruth Tevlin ${ }^{1,2}$, Michael T. Longaker ${ }^{1,2,3}$ and Derrick C. Wan ${ }^{1,2 *}$ \\ ${ }^{1}$ Division of Plastic and Reconstructive Surgery, Stanford University School of Medicine, Stanford, CA, United States, \\ ${ }^{2}$ Hagey Laboratory for Pediatric Regenerative Medicine, Department of Surgery, Stanford University School of Medicine, \\ Stanford, CA, United States, ${ }^{3}$ Institute for Stem Cell Biology and Regenerative Medicine, Stanford University School of \\ Medicine, Stanford, CA, United States
}

Defects of the craniofacial skeleton arise as a direct result of trauma, diseases, oncological resection, or congenital anomalies. Current treatment options are limited, highlighting the importance for developing new strategies to restore form, function, and aesthetics of missing or damaged bone in the face and the cranium. For optimal reconstruction, the goal is to replace "like with like." With the inherent challenges of existing options, there is a clear need to develop alternative strategies to reconstruct the craniofacial skeleton. The success of mesenchymal stem cell-based approaches has been hampered by high heterogeneity of transplanted cell populations with inconsistent preclinical and clinical trial outcomes. Here, we discuss the novel characterization and isolation of mouse skeletal stem cell (SSC) populations and their response to injury, systemic disease, and how their re-activation in vivo can contribute to tissue regeneration. These studies led to the characterization of human SSCs which are able to self-renew, give rise to increasingly fate restricted progenitors, and differentiate into bone, cartilage, and bone marrow stroma, all on the clonal level in vivo without prior in vitro culture. SSCs hold great potential for implementation in craniofacial bone tissue engineering and regenerative medicine. As we begin to better understand the diversity and the nature of skeletal stem and progenitor cells, there is a tangible future whereby a subset of human adult SSCs can be readily purified from bone or activated in situ with broad potential applications in craniofacial tissue engineering.

Keywords: skeletal stem cells, skeletal progenitors, osteoprogenitors, craniofacial surgery, tissue regeneration

\section{INTRODUCTION}

Defects of the craniofacial skeleton may arise following trauma, diseases, oncological resection, or may be secondary to congenital anomalies. The craniofacial skeleton is an anatomically complex region with critical functional and cosmetic importance and thus, craniofacial reconstruction proves challenging. Calvarial defects impact protection of the central nervous system, meninges and brain whereas orbital defects can impact eye protection, support and protection. Maxillary and mandibular defects can impact the basic functions of speech, swallow and breathing in addition to cosmesis. Current treatment options are limited which highlights the importance of developing novel strategies to restore form, function, and aesthetics of missing or damaged bone in the face and 
the cranium. Reconstructive surgeons perform in excess of 50,000 craniofacial procedures annually to treat both congenital anomalies and head and neck defects (1), and the global bone graft and substitutes market size is expected to exceed $\$ 4$ billion by 2026 (2).

To achieve optimal reconstruction, the goal is to replace "like with like" (3). Autologous tissue is preferred for reconstruction, but this approach can lead to significant donor site morbidity, may still result in resorption, and has limited availability $(4,5)$. As there is a finite supply of bone, alternative strategies have been pursued including cadaveric allografts tissue and alloplastic bone substitutes. Allografts are fraught with unpredictable rates of bone resorption and when processed to reduce immunogenicity, osteo-inductive factors are also deactivated. Alloplastic bone substitutes are complicated by infection, risk of extrusion, and an inability to grow with a developing child (6). With the inherent challenges of established options, there is a definitive need to develop alternative strategies to reconstruct craniofacial tissues.

Tissue engineering supports tissue regenerative processes by implementing cells, scaffolds, growth factors, gene manipulation, or combinations of these elements to reconstruct defects $(5,7,8)$. Thus, by engineering and delivering tissues with or without cells capable of replacing damaged bone, regenerative medicine offers the potential to treat critical-sized bone defects which pose challenging clinical dilemmas. In the field of regenerative tissue engineering, there are multiple issues to consider in the creation of a functional, implantable replacement tissue. Importantly, there must exist an easily accessible, readily abundant cell source with the capacity to express the phenotype of the desired tissue and a biocompatible scaffold to deliver the cells to the skeletal defect (5).

Stem cells capable of skeletal regeneration are ideal cells for tissue engineering. Stem cells display tissue-specific differentiation patterns and have an ability to proliferate in response to certain physiological cues, critical to tissue regeneration (9). Adult stem cells have been isolated from multiple tissues including the central nervous system (10), skeletal muscle (11), adipose tissue (12), and from bone (13-17). Bones undergo myriad biologically important steps throughout their life cycle, such as morphogenesis and development, explosive growth and functional maturation, maintenance and repair of proper architecture and function, thus supporting the existence of adult skeletal stem cells $(18,19)$. There is a constant demand for differentiated cells at each sequential step so that bones can remodel, grow and become stronger, while maintaining their strength and function throughout life (19).

In this review, we will focus on the novel characterization of SSC populations with potential for implementation in craniofacial bone tissue engineering and regenerative medicine and describe their response to injury, systemic disease, and how their re-activation can contribute to tissue regeneration.

\section{MESENCHYMAL STEM CELLS}

The most frequently studied cells for potential tissue regeneration are the mesenchymal stromal/stem cells (MSCs) which are reported to have the capacity to generate bone, cartilage, and fat, among other types of stromal cells (20). For decades, we and myriad others have investigated MSCs as an abundant pluripotent source for potential use in tissue engineering and regenerative medicine (21-23). MSCs have been reportedly isolated from the heart, liver, synovium, placenta, pancreas, cord blood (24), however the cells which encompass MSCs are heterogenous and their ability to differentiate into osteogenic progenitors occurs is not uniform (25). While preclinical trials using MSCs continue, a number of questions related to MSC characterization and their implementation are largely unresolved $(18,26)$. Although the mechanisms underlying the therapeutic effects of MSCs are not well-characterized in disease models, the search for consistent cell-surface markers to identify and harvest source-specific MSCs is paramount to improve patient outcomes. The success of MSC-based approaches has been hindered by heterogeneity of the transplanted cell populations which is mainly attributable to the lack of consistency in tissue source, but may also be a result of discrepancies in approaches to detection of a pure cellular population and isolation of prospective stem cells $(18,27)$.

\section{SKELETAL STEM CELL CHARACTERIZATION}

The terms skeletal stem cells (SSCs) and MSCs are not equivalent and thus, should not be used interchangeably, as they report different skeletogenic populations (18). SSCs are distinguished by the local restriction of cells to bone with the ability to form an environment for hematopoiesis, the ability to self-renew on the clonal level, and the ability to demonstrate multipotency under in vivo conditions. Pioneering studies led by Friedenstein et al. established the presence of colony forming skeletogenic cells in the 1980's (28). In the past decade, significant progress has been made in the characterization of cells capable of giving rise to bone, cartilage, and bone marrow stroma, hereafter referred to as skeletal stem cells $(15,16,29-32)$. In 2015, following a combination of rigorous single cell analyses and lineage tracing technologies, our laboratory characterized the mouse skeletal stem cell (mSSC), a single cell capable of giving rise to bone, cartilage, and bone marrow stroma in mice (13). The mSSC immunophenotype is characterized by differential expression of AlphaV, Thy, 6C3, CD 15, and CD 200 (13). These cells are distinct from the MSC in that they do not give rise to adipocytes, fibroblasts, hematopoietic, or muscle cells (33). Furthermore, mSSCs defined a lineage tree of skeletal stem and increasingly fate-restricted progeny, which had differential ability to generate bone, cartilage, and bone marrow stroma (Figure 1). In addition, pathways were defined that play a role in directing the differentiation of skeletal stem and progenitor cells. Specifically, to address a large unmet clinical need, osteogenesis and chondrogenesis could be directed from mSSCs through manipulation of local niche signaling (13).

Building upon these findings, Worthley et al. demonstrated that the expression of a bone morphogenetic protein (BMP) antagonist, Gremlin 1, defines a specific population of SSCs in the 


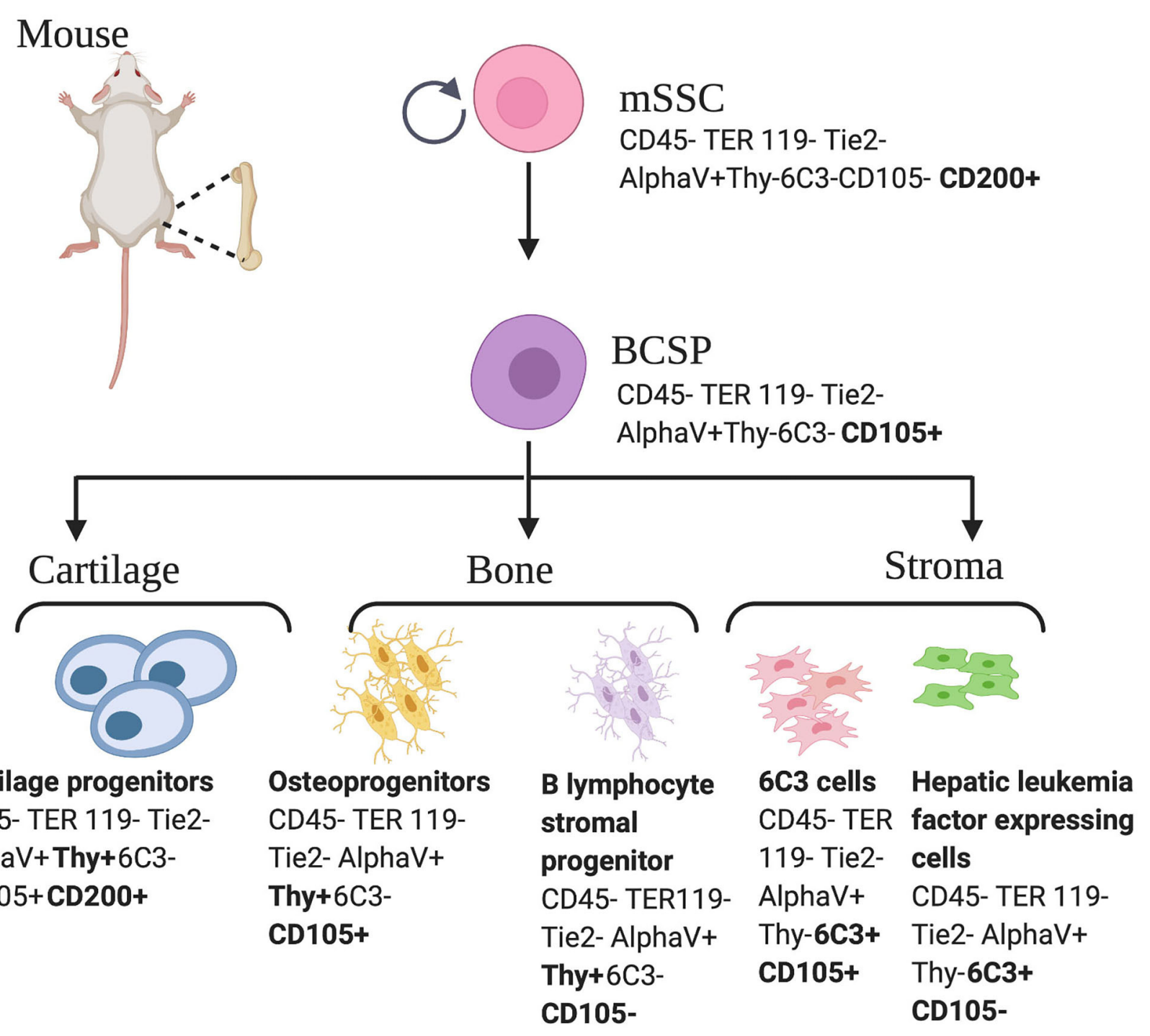

FIGURE 1 | Mouse skeletal stem cell and downstream progenitors (13). Skeletal stem cells (SSCs) and their progenitors can be isolated from mice bones on the basis of distinctive immunophenotypes using flow cytometry. The mSSC is shown at the apex of the stem cell tree with differentiation into increasing fate restricted progenitors. The multipotent bone cartilage and stromal progenitor (BCSP) gives rise to mouse cartilage progenitors, mouse osteoprogenitors, mouse B lymphocyte stromal progenitors, mouse $6 \mathrm{C} 3$ stromal cells, and mouse hepatic leukemia factor expressing cells. The immunophenotype of the cell surface markers are shown for each cell $(13,34)$. This figure is adapted from Chan et al. (13).

mouse bone marrow (15). The so-called "osteochondroreticular" (OCR) cells self-renew, generate osteoblasts, chondrocytes, and bone marrow stromal cells, but do not give rise to adipocytes. These OCR stem cells are concentrated within the metaphysis of long bones and are implicated in bone development, remodeling, and fracture repair. OCR cells show great theoretical promise for skeletal tissue engineering, as these cells have been harvested from a donor animal, expanded in vitro, and transplanted both directly and serially into the femora of fractured recipient animals, resulting in osteochondral differentiation in the callus (15). Mizuhashi et al. also characterized a population of PTHrP+ chondrocytes in mice that possessed stem cell characteristics with overlapping immunophenotype to the $\mathrm{mSSC}$ as characterized by
Chan et al. (13) and Mizuhashi et al. (35). On comparison of the mSSC to the mouse hematopoietic stem cell (HSC) tree, it is reasonable to deduce that mSSCs defined by varying surface markers and lineage tracing techniques reported by different groups may indeed overlap and/or fit together in a more complex lineage tree, similar to that of the HSC. As many studies confirmed that specific adult SSCs exist in the mouse, and given the conservation of skeletal genes in mice and humans (36), the search for human SSCs continued.

Early efforts to isolate non-HSCs in human bone relied on the ability of bone marrow cells to adhere to plastic plates. However, these cultures of MSCs contained heterogenous mixtures of cells with indeterminate potential and inconsistent contribution 
to many overlapping lineages such as bone, cartilage, fat, muscle, fibroblast, endothelial cells, and stroma. Likely, these cells represent a population comprised of multiple distinct stem cells rather than a uniform purified skeletal stem cell (14). Identification of several specific cell-surface proteins led to enrichment for skeletogenic activity in MSCs and ultimately resulted in the identification of osteogenic, chondrogenic, and adipogenic lineages $(14,37)$. Building upon these findings and following characterization of the $\mathrm{mSSC}$, significant progress was made to identify a homogenous human SSC population and its lineally related downstream progenitors. Using a set of mSSC-specific genes and their human orthologs in combination with rigorous single cell analyses, FACS isolation, and in vivo differentiation assays, Chan et al. were enabled to define an immunophenotype that characterized the human skeletal stem and increasingly fate-restricted progenitor cells characterized by differential expression of PDPN, CD146, CD 73, and CD164 (Figure 2) (14).

\section{SKELETAL STEM AND PROGENITOR CELL RESPONSE TO INJURY}

Stem and progenitor cells mediate homeostasis and regeneration in postnatal tissue and alterations in tissue microenvironment are known to influence stem cell behavior. A true SSC should respond to injury, and previous studies report that bone injury induces progenitor expansion $(32,38)$. Skeletal fracture may thus activate a distinct subset of skeletal stem and progenitor cells in mice that mediate tissue regeneration and repair (39). Worthley et al. have described OCR SSCs to be involved in fracture repair (15). However, as endochondral bone formation has been found to occur through the bone cartilage and stromal progenitor (BCSP), which is derived from the SSC (13), these cells may also participate in long bone fracture healing. Using a model of transverse, mid-diaphyseal femoral fractures with intramedullary fixation, progenitor expansion was observed to precede ossified callus formation at multiple time points (39).

Murphy et al. also identified that mSSCs could be re-activated in the setting of a microfracture bone injury (40). Marecic et al. further identified injury induced phenotypic changes in the BCSP progenitor cells. Notably, the progenitor cells harvested from fracture calluses had significantly increased plating efficiency, as determined by colony number, significantly greater viability, and markedly reduced apoptotic activity. In addition, fractureinduced BCSPs had greater osteogenic potential when assayed both in vitro and in vivo in a heterotopic kidney capsule transplantation model. Using transcriptional and translational analyses, a highly potent regenerative cell type, the fractureBCSP (f-BCSP), was thus identified that recapitulated many gene expression patterns involved in perinatal skeletogenesis (39).

Building on this work in human bone, hSSCs have also been found to be amplified in soft callus fracture specimens when compared to their frequency in uninjured skeletal tissues that were obtained from patients undergoing bone graft procedures (14). To further examine the activation of hSSC in response to injury, our group has established a new human bone xenograft mouse model to evaluate the effects of skeletal injury in human limb bones in a more controlled setting. Following transplantation and engraftment of human fetal phalangeal grafts (obtained from 18-weeks-old fetuses) into the flanks of 5-days old immunodeficient mice, uni-cortical fractures were induced on the xenografted phalangeal bones. This resulted in significant localized expansion of hSSCs relative to unfractured areas in the same bone. Therefore, consistent fracture induced expansion of both mSSC and hSSC in response to injury has been observed $(14,39)$, which has also been replicated in other SSC populations $(15,41)$.

\section{SKELETAL STEM AND PROGENITOR CELL NICHE RESPONSE TO SYSTEMIC CONDITIONS}

Schofield first proposed the concept of a stem cell "niche" where stem cells are supported by a specialized micro-environment within tissues which promote their long-term stem cell activity $(15,42)$. Niches are able to balance the production of stem and progenitor cells to maintain tissue equilibrium (43) and niche activity is carefully regulated to ensure appropriate stem cell function $(42,44,45)$. Tissue injury demonstrates the dynamic relationship between stem cells and their niches. A decline in niche function and the inability to guide local self-renewal contribute to reduced tissue homeostasis and repair in a number of systems $(15,46)$. In addition, changes in circulating systemic factors have also led to decreased stem cell activity (42, 47-52).

It has been proposed that interactions between SSCs and their downstream progeny act to maintain an appropriate pool of SSCs through paracrine signaling (53). In a mouse model of diabetes mellitus, high serum concentrations of tumor necrosis factor alpha has been shown to directly repress the expression of Indian hedgehog (Ihh) in mSSCs and in their downstream progenitors, leading to deficient niche signaling and impaired SSC bone regeneration (54). Furthermore, conservation of repressed Ihh signaling in human skeletal progenitors obtained from freshly dissected femoral and knee specimens in osteoarthritic diabetic patients undergoing total joint arthroplasty has been appreciated (54). In mouse models of obesity, ectopic adipocyte accumulation in the bone marrow is believed to contribute to age-related impairment of bone regeneration (55-57).

Heterotopic ossification ( $\mathrm{HO})$, defined by the formation of extra-skeletal bone which occurs in patients with substantial trauma or BMP type 1 receptor mutations $(58,59)$, likewise highlights the interplay between progenitor cells and their associated niche in the pathogenesis of disease. Agarwal et al. examined if known mouse osteoprogenitor cells which contribute to normal bone development are involved in $\mathrm{HO}$ (60). Importantly, BCSPs were found to be enriched at sites of $\mathrm{HO}$, participating in de novo bone formation both in a trauma-induced mouse model for $\mathrm{HO}$ and in a transgenic mouse expressing a constitutively active type I Activin A receptor involved in BMP signaling leading to increased $\mathrm{HO}$ susceptibility. They further demonstrated that the BCSPs in HO undergo osteogenic and chrondrogenic differentiation on the basis of 


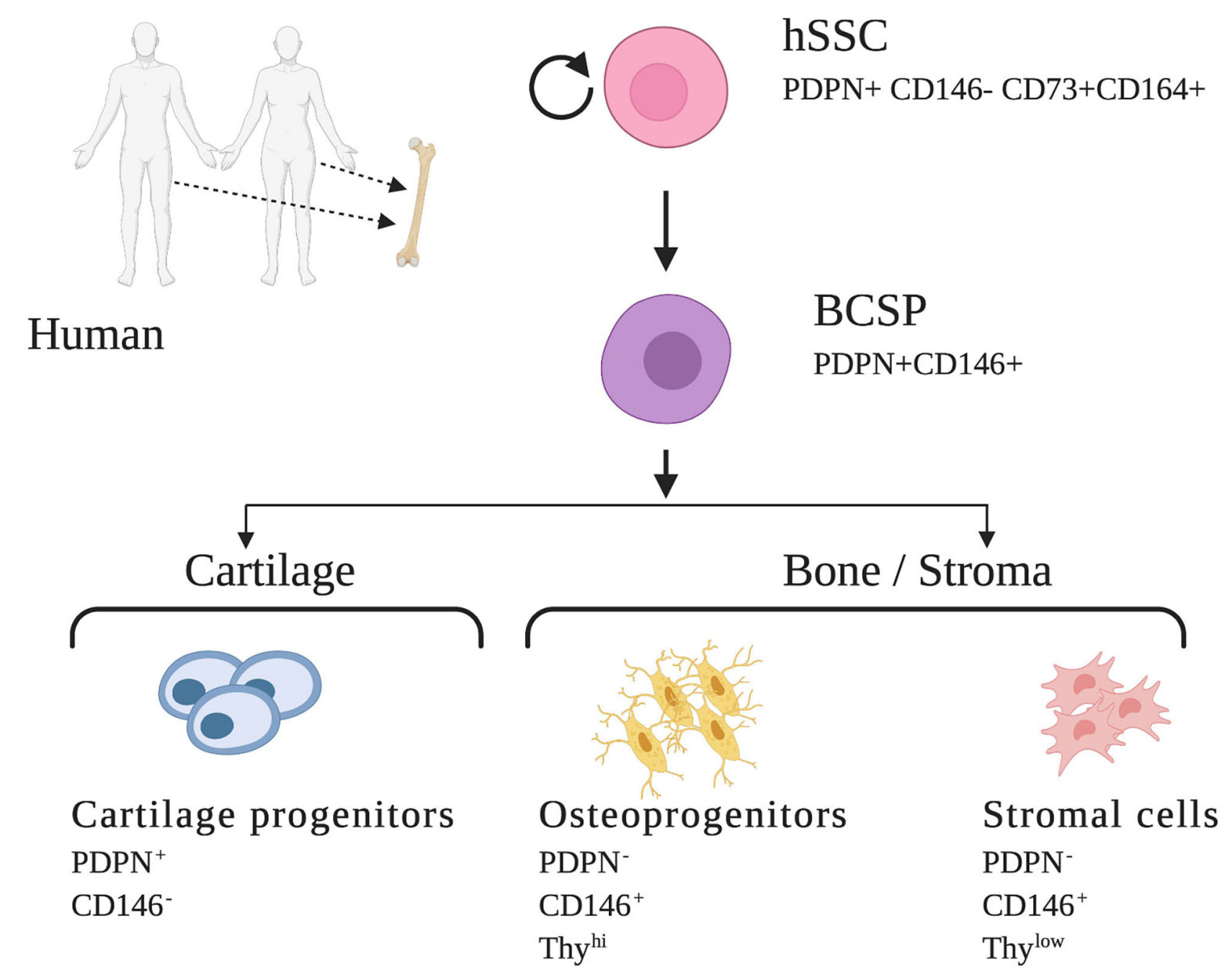

FIGURE 2 | Human skeletal stem cell and downstream progenitors (14). Skeletal stem cells (SSCs) and their progenitors can be isolated from human bones on the basis of distinctive immunophenotypes using flow cytometry. The hSSC is shown at the apex of the stem cell tree with differentiation into increasing fate restricted progenitors. The multipotent bone cartilage and stromal progenitor (BCSP) gives rise to cartilage progenitors, osteoprogenitors, and stromal cells. The immunophenotype of the cell surface markers are shown for each cell $(14,34)$. This figure is adapted from Chan et al. (14).

osteocalcin, osterix and sox9 expression. These results further support that BCSPs play a conserved role in post-natal bone formation given their shared presence in normally developing bone, healing fracture callus, and in de novo ectopic bone formation (60).

The capacity for skeletal tissue repair and regeneration declines with aging and thus bone repair is deficient in aging patients. Josephson et al. recently delineated that age-associated inflammation ("inflamm-aging") is the main culprit for skeletal stem and progenitor cell dysfunction seen with advancing age (47). In contrast to the organized inflammatory response which follows trauma, chronic pro-inflammatory cytokines inhibit regeneration in a variety of tissues including bone (61). Josephson et al. identified that NF- $\kappa \beta$ plays a central role in inflammaging and that modification of the inflammatory niche represents a valid translational approach to functionally rejuvenate aged skeletal stem and progenitor cells. By using a pharmacological approach inhibiting NF- $\kappa \beta$ activation (sodium salicyclate), they demonstrated a functional rejuvenation of aged skeletal stem and progenitor cells with decreased senescence, increased stem and progenitor cell proliferation and increased osteogenesis (61).

Ambrosi et al. analyzed and isolated hSSCs from callus tissue of 61 patients ranging from 13 to 94 years for functional and molecular studies (62). These studies revealed that advanced age significantly correlated with reduced osteogenic and chondrogenic potential. Their results suggest that geriatric hSSCs preferably acquire a fibrogenic fate, which leads to deficient healing. Transcriptomic comparisons revealed downregulation of skeletogenic pathways such as Wnt and upregulation of senescence-related pathways in older vs. 
young hSSCs (62). Sirtl has been proposed to increase stress resistance and cell death protection expression and was downregulated in geriatric hSSCs. As Sirt1 functions as a histone deacetylase, functional differences in hSSC may be epigenetically regulated during aging. Previous studies have shown increased lifespan and delayed aging by preserving Sirt 1 expression (63-66). Consequences of hSSC aging may be reversible as agonists of the Sirtl histone deacetylase significantly improved osteogenic differentiation of aged-impaired hSSCs (62).

Aging may also have a detrimental impact on bone by acting on the hematopoietic niche. Aged bone stroma can be affected by age-related disruption of the hematopoietic niche where myeloid differentiation is dominant during hematopoietic stem and progenitor cell expansion (18). The age related change in niche signaling has a resultant downstream effect of increased osteoclastogenesis in the setting of diminished skeletal stem and progenitor cell pool, thus further reducing skeletal bone mass (18). Taken together, in aging there are changes in local niche signaling that lead to skewing of skeletal lineages to a fibroblastic phenotype, increased osteoclastogenesis and pro-inflammatory cytokine production which reduce bone regeneration (18), reflecting the importance of the niche on skeletal homeostasis and repair/regeneration.

\section{SKELETAL STEM CELL RESPONSE TO RADIATION}

Osteonecrosis of the jaw can lead to significant loss of bone, loss of teeth and aesthetic deformity, resulting in significant disability and reduced quality of life (67). It is most commonly associated with radiation, when the radiation dose exceeds 50 Gy (68). Radiation, an important modality for treatment of many malignancies, has been shown to result in disorganization and coarsening of the stromal trabecular architecture (69), and this is also associated with a time-dependent loss of skeletal progenitors (70), limiting healing, and impairing normal homeostasis. Furthermore, this bone dysfunction has been found to correlate with reduced BCSP frequency in a mouse model of hind limb radiation prior to fracture injury. Reduced callus formation, prolonged healing, and significantly reduced BCSP osteoprogenitor expansion in the setting of prior radiation have all been observed (39), punctuating the important interplay between skeletal progenitors and the stromal niche. Sclerostin, a Wnt antagonist, has been recently proposed as a new target to reduce radiation induced osteopenia (71). Sclerostin knockout mice are insensitive to radiation (72-74). Chandra et al. hypothesized that neutralization of circulating sclerostin with a monoclonal antibody, leading to activation of the canonical Wnt signaling in bone, could treat osteoporosis by enhancing $\mathrm{Wnt} / \beta$-catenin signaling and resulting in bone protection (71). The effect of Sclerostin and relevant methods of antagonism on skeletal stem cells and their progenitors offer an interesting focus of further investigation to aid patients undergoing radiation of the craniofacial skeleton.

\section{SKELETAL STEM CELL RE-ACTIVATION IN ENDOGENOUS MODELS}

During regenerative processes, adult stem cell populations change not only in proliferation and location but also in their underlying gene-regulatory programs $(75,76)$, and in response to injury, stem cells may reactivate a greater potential for differentiation (77). Distraction osteogenesis (DO), an endogenous form of bone tissue engineering, has been used clinically to generate new bone. It was initially developed by Ilizarov for lengthening long bones after a chance discovery following a patient's misunderstanding of post-operative instructions (78). Following placement of an external fixator, rather than compressing a bone fracture along its long axis, gradual guided separation of osteogenic fronts was found to result in de novo bone growth across the gap $(78,79)$. In DO, a surgical fracture (osteotomy) is created and subsequent expansion along its long axis is performed which creates mechanical stimulation, inducing biologic responses promoting bone regeneration. $\mathrm{DO}$ is divided into three key steps: a latency period for callus development, a distraction period of gradual lengthening, and a consolidation period that allows the stretched callus to mineralize. Distraction forces have been found to promote callus reorganization with a fibrous center, a highly vascularized zone of developing bone, and a mineralizing zone of bone undergoing primary bone formation adjacent to the uncut host bone. When tension is applied to move the bony segments apart, mineralization occurs from the bony ends toward the fibrous center.

The use of DO in the mandible has increased over the past two decades to treat severe bone deficiency, as occurs in Pierre Robin Sequence (PRS) or other craniofacial syndromes associated with micrognathia $(79,80)$. Historically children with PRS required tracheostomies, but the implementation of DO has obviated this need to address the compromised airway in newborns with low operative morbidity and improved QOL (81). DO has also been used in distraction of the midface (maxillary deficiency and craniofacial synostosis), zygoma (Treacher Collins syndrome), maldevelopment of the cranial vault (craniofacial synostosis), and edentulous mandible and maxillary alveoli $(79,81)$. Importantly, major bony structures of the face, including the maxilla and mandible, are derived from neural crest, and re-activation of neural crest transcriptional programs may be important for repair and regeneration of these skeletal elements $(82,83)$. In a mouse model of mandibular DO, Ransom et al. demonstrated that adult mSSCs revert to a developmentally plastic state, activating an embryonic neural crest-like transcriptional pattern (84). This was primarily driven through mechanical stimulation of focal adhesion kinase-mediated signaling pathways. Of note, the bone regenerated following DO may be associated with complications such as relapse, whereby the final length of the bone diminishes after the consolidation period. With a better understanding of the underlying biomechanics of mandibular osteogenesis and regulatory cues guiding SSCs, 
innovative clinical solutions in craniofacial skeletal regeneration can be developed.

The craniofacial sutures are a unique skeletal structure which continue to pose complex clinical dilemma in the setting of craniosynostosis, a condition which results from pathologic premature fusion of the cranial sutures. It has long been postulated that the suture mesenchyme is the niche of the SSCs essential for cranial morphogenesis. Recently an Axin-2 expressing stem cell population has been isolated from sutures and has been shown to contribute directly to calvarial defect repair and skeletal regeneration in a cell autonomous fashion (85). The only other marker to date capable of marking the cell population contributing to calvarial maintenance and injury repair is Gli1 (86). Maruyama et al. demonstrated that Axin 2 and Gli1 are co-expressed in a putative suture stem cell population which is predominantly found in calvarial bones, rather than bones of the axial skeleton and which is activated in the setting of calvarial injury $(85,86)$. In addition, Debnath et al. characterized the "periosteal stem cell," which they isolated from long bones and calvaria of mice (87). The PSC displays clonal multipotency and self-renewal and is activated in the setting of long bone injury, highlighting a key characteristic shared by other SSC populations (87). Further studies of clinical samples harvested from patients with craniosynostosis also suggest that Axin 2 may reasonably represent a marker for the stem cell population that undergoes depletion during premature ossification process occurring in craniosynostosis (88). While this work is still in its infancy, it suggests that SSC activation may indeed be detrimental in this clinical setting, contributing to the development of craniosynostosis $(85,86$, 88).

Another complex area for craniofacial tissue engineering is the temporomandibular joint (TMJ) which is imperative for daily functions such as talking and eating. The TMJ is a complex joint formed between the temporal bone and the mandibular condyle that can be affected by inflammatory and degenerative arthritis and can affect $8-16 \%$ of the population (89-91). In the advanced stage, surgical interventions such as condylotomy and arthroplasty are recommended but in earlier stages, palliative therapies are pursued rather than restorative therapies. Recently, Murphy et al. demonstrated that aging is associated with a progressive loss of SSCs and diminished chondrogenesis in the joints of both humans and mice (40). They activated a regenerative response by performing microfracture surgery where the surgeon drills through denuded cartilage into the marrow cavity. They reported that microfracture surgery alone tended to form fibrous tissue but with localized co-delivery of BMP2 and soluble VEGF receptor antagonist in addition to microfracture, they were able to skew the resident stem cell differentiation toward articular cartilage (40). These data suggest that microfracture along with local delivery of BMP2 and soluble VEGF antagonism could hold promise for patients who suffer with TMJ arthritis and induce de novo articular cartilage formation (40).

\section{LOOKING TO THE FUTURE OF CRANIOFACIAL TISSUE ENGINEERING}

Mouse studies continue to power our understanding of skeletal development and regeneration. However, the characterization of human SSCs that have been identified in fetal tissue, adult fracture callus, and in xenograft models of injury holds enormous promise for a paradigm shift in the treatment of craniofacial defects and the understanding of pathogenetic mechanisms. In vitro methods to derive tissue specific stem cells, expand patient derived stem cells, and protocols to differentiate them into functional tissues are highly important topics in stem cell research and bioengineering. However, as has been seen with bone marrow derived MSCs (92), in vitro cell culture experiments are flawed with regard to the assessment of in vivo cell behavior and should not be considered as evidence of stem cell activity (18). SSCs should be able to self-renew, give rise to increasingly fate restricted progenitors, and differentiate into osteoblasts/osteocytes and chondrocytes, all on the clonal level in vivo without prior in vitro culture (24). We are only beginning to understand the diversity and the nature of skeletal stem and progenitor cells and how they actually behave in vivo. The discovery of a subset of human adult SSCs that can be readily purified from bone has broad potential applications in regenerative medicine. The hSSC exhibits all of the hallmarks of an early skeletal stem cell that can give rise to downstream lineage committed progenitors that may be beneficial in skeletal replacement therapies. Further studies, aiming to understand the mechanisms by which SSCs interact with the environment, interact with downstream progenitors and regulate their lineage choice under disease conditions are likely to unlock the regenerative potential of these cells and open up further therapeutic avenues for craniofacial skeletal tissue engineering.

\section{AUTHOR CONTRIBUTIONS}

RT, ML, and DW wrote and edited the manuscript. All authors contributed to the article and approved the submitted version.

\section{FUNDING}

This work was supported by the Oak Foundation and the Hagey Laboratory for Pediatric Regenerative Medicine. RT was also supported by the Plastic Surgery Research Council Research Fellowship Grant and the Stanford University Tissue Engineering and Center of Excellence Research Grant. ML was supported by NIH Grant R01 DE026730 and R01 DE027323.

\section{ACKNOWLEDGMENTS}

All figures were created with Biorender.com. We would like to thank Virginia Ford and Paulo Pereira for their dedication to excellent lab management and administration. 


\section{REFERENCES}

1. ASPS. Plastic Surgery Statistics American Society of Plastic and Reconstructive Surgeons. Arlington Heights, IL: American Society of Plastic Surgeons (2019).

2. Research PM. Bone Grafts and Substitutes Market Size, Share \& Trends Analysis Report By Material Type (Natural, Synthetic); By Application Type (Spinal Fusion, Craniomaxillofacial, Long Bone); By Region-Segment Forecast, 2020-2026. San Francisco, CA: Grand View Research, Inc. (2020).

3. FitzGibbon GM. The commandments of Gillies. Br J Plast Surg. (1968) 21:226-39. doi: 10.1016/S0007-1226(68)80028-1

4. Borrelli MR, Hu MS, Longaker MT, Lorenz HP. Tissue engineering and regenerative medicine in craniofacial reconstruction and facial aesthetics. $J$ Craniofac Surg. (2020) 31:15-27. doi: 10.1097/SCS.0000000000005840

5. Tevlin R, Walmsley GG, Marecic O, Hu MS, Wan DC, Longaker MT. Stem and progenitor cells: advancing bone tissue engineering. Drug Deliv Transl Res. (2016) 6:159-73. doi: 10.1007/s13346-015-0235-1

6. Oppenheimer AJ, Tong L, Buchman SR. Craniofacial bone grafting: Wolff's law revisited. Craniomaxillofac Trauma Reconstr. (2008) 1:4961. doi: 10.1055/s-0028-1098963

7. Tevlin R, Atashroo D, Duscher D, Mc Ardle A, Gurtner GC, Wan DC, et al. Impact of surgical innovation on tissue repair in the surgical patient. Br J Surg. (2015) 102:e41-55. doi: 10.1002/bjs.9672

8. Walmsley GG, McArdle A, Tevlin R, Momeni A, Atashroo D, Hu MS, et al. Nanotechnology in bone tissue engineering. Nanomedicine. (2015) 11:125363. doi: 10.1016/j.nano.2015.02.013

9. Cheung TH, Rando TA. Molecular regulation of stem cell quiescence. Nat Rev Mol Cell Biol. (2013) 14:329-40. doi: 10.1038/nrm3591

10. Daniela F, Vescovi AL, Bottai D. The stem cells as a potential treatment for neurodegeneration. Methods Mol Biol. (2007) 399:199-213. doi: 10.1007/978-1-59745-504-6_14

11. Chargé SB, Rudnicki MA. Cellular and molecular regulation of muscle regeneration. Physiol Rev. (2004) 84:209-38. doi: 10.1152/physrev.00019.2003

12. Zuk PA, Zhu M, Ashjian P, De Ugarte DA, Huang JI, Mizuno H, et al. Human adipose tissue is a source of multipotent stem cells. Mol Biol Cell. (2002) 13:4279-95. doi: 10.1091/mbc.e02-02-0105

13. Chan CK, Seo EY, Chen JY, Lo D, McArdle A, Sinha R, et al. Identification and specification of the mouse skeletal stem cell. Cell. (2015) 160:28598. doi: 10.1016/j.cell.2014.12.002

14. Chan CKF, Gulati GS, Sinha R, Tompkins JV, Lopez M, Carter AC, et al. Identification of the human skeletal stem cell. Cell. (2018) 175:43-56 e21. doi: 10.1016/j.cell.2018.07.029

15. Worthley DL, Churchill M, Compton JT, Tailor Y, Rao M, Si Y, et al. Gremlin 1 identifies a skeletal stem cell with bone, cartilage, and reticular stromal potential. Cell. (2015) 160:269-84. doi: 10.1016/j.cell.2014.1 1.042

16. Méndez-Ferrer S, Michurina TV, Ferraro F, Mazloom AR, Macarthur BD, Lira SA, et al. Mesenchymal and haematopoietic stem cells form a unique bone marrow niche. Nature. (2010) 466:829-34. doi: 10.1038/nature09262

17. Duchamp de Lageneste O, Julien A, Abou-Khalil R, Frangi G, Carvalho C, Cagnard $\mathrm{N}$, et al. Periosteum contains skeletal stem cells with high bone regenerative potential controlled by Periostin. Nat Commun. (2018) 9:2018. doi: 10.1038/s41467-018-03 124-z

18. Ambrosi TH, Longaker MT, Chan CKF. A revised perspective of skeletal stem cell biology. Front Cell Dev Biol. (2019) 7:2019. doi: 10.3389/fcell.2019.00189

19. Ono N, Balani DH, Kronenberg HM. Stem and progenitor cells in skeletal development. Curr Top Dev Biol. (2019) 133:1-24. doi: 10.1016/bs.ctdb.2019.01.006

20. Pittenger MF, Mackay AM, Beck SC, Jaiswal RK, Douglas R, Mosca JD, et al. Multilineage potential of adult human mesenchymal stem cells. Science. (1999) 284:143-7. doi: 10.1126/science.284.5411.143

21. Li S, Huang KJ, Wu JC, Hu MS, Sanyal M, Hu M, et al. Peripheral bloodderived mesenchymal stem cells: candidate cells responsible for healing critical-sized calvarial bone defects. Stem Cells Transl Med. (2015) 4:35968. doi: 10.5966/sctm.2014-0150

22. Tataria M, Quarto N, Longaker MT, Sylvester KG. Absence of the p53 tumor suppressor gene promotes osteogenesis in mesenchymal stem cells. J Pediatr Surg. (2006) 41:624-32. doi: 10.1016/j.jpedsurg.2005.12.001
23. Warren SM, Nacamuli RK, Song HM, Longaker MT. Tissue-engineered bone using mesenchymal stem cells and a biodegradable scaffold. J Craniofac Surg. (2004) 15:34-7. doi: 10.1097/00001665-200401000-00012

24. Bianco P, Robey PG, Simmons PJ. Mesenchymal stem cells: revisiting history, concepts, and assays. Cell Stem Cell. (2008) 2:313-9. doi: 10.1016/j.stem.2008.03.002

25. McLeod CM, Mauck RL. On the origin and impact of mesenchymal stem cell heterogeneity: new insights and emerging tools for single cell analysis. Eur Cell Mater. (2017) 34:217-31. doi: 10.22203/eCM.v034a14

26. Sacchetti B, Funari A, Remoli C, Giannicola G, Kogler G, Liedtke S, et al. No identical "mesenchymal stem cells" at different times and sites: human committed progenitors of distinct origin and differentiation potential are incorporated as adventitial cells in microvessels. Stem Cell Rep. (2016) 6:897913. doi: 10.1016/j.stemcr.2016.05.011

27. Galipeau J, Sensébé L. Mesenchymal stromal cells: clinical challenges and therapeutic opportunities. Cell Stem Cell. (2018) 22:824-33. doi: 10.1016/j.stem.2018.05.004

28. Friedenstein AJ, Chailakhyan RK, Gerasimov UV. Bone marrow osteogenic stem cells: in vitro cultivation and transplantation in diffusion chambers. Cell Tissue Kinet. (1987) 20:263-72. doi: 10.1111/j.1365-2184.1987.tb01309.x

29. Bianco P. "Mesenchymal" stem cells. Annu Rev Cell Dev Biol. (2014) 30:677704. doi: 10.1146/annurev-cellbio-100913-013132

30. Chan CK, Lindau P, Jiang W, Chen JY, Zhang LF, Chen CC, et al. Clonal precursor of bone, cartilage, and hematopoietic niche stromal cells. Proc Natl Acad Sci USA. (2013) 110:12643-8. doi: 10.1073/pnas.1310212110

31. Morrison JI, Lööf S, He P, Simon A. Salamander limb regeneration involves the activation of a multipotent skeletal muscle satellite cell population. J Cell Biol. (2006) 172:433-40. doi: 10.1083/jcb.200509011

32. Park D, Spencer JA, Koh BI, Kobayashi T, Fujisaki J, Clemens TL, et al. Endogenous bone marrow MSCs are dynamic, fate-restricted participants in bone maintenance and regeneration. Cell Stem Cell. (2012) 10:25972. doi: $10.1016 /$ j.stem.2012.02.003

33. Tichy ED, Mourkioti F. Human skeletal stem cells: the markers provide some clues in the hunt for hidden treasure. Cell Stem Cell. (2018) 23:4623. doi: 10.1016/j.stem.2018.09.006

34. Salhotra A, Shah HN, Levi B, Longaker MT. Mechanisms of bone development and repair. Nat Rev Mol Cell Biol. (2020) 21:696-711. doi: 10.1038/s41580-020-00279-w

35. Mizuhashi K, Ono W, Matsushita Y, Sakagami N, Takahashi A, Saunders TL, et al. Resting zone of the growth plate houses a unique class of skeletal stem cells. Nature. (2018) 563:254-8. doi: 10.1038/s41586-018-0662-5

36. Monaco G, van Dam S, Casal Novo Ribeiro JL, Larbi A, de Magalhães JP. A comparison of human and mouse gene co-expression networks reveals conservation and divergence at the tissue, pathway and disease levels. BMC Evol Biol. (2015) 15:259. doi: 10.1186/s12862-015-0534-7

37. Lv FJ, Tuan RS, Cheung KM, Leung VY. Concise review: the surface markers and identity of human mesenchymal stem cells. Stem Cells. (2014) 32:140819. doi: 10.1002/stem.1681

38. Zhou BO, Yue R, Murphy MM, Peyer JG, Morrison SJ. Leptin-receptorexpressing mesenchymal stromal cells represent the main source of bone formed by adult bone marrow. Cell Stem Cell. (2014) 15:15468. doi: 10.1016/j.stem.2014.06.008

39. Marecic O, Tevlin R, McArdle A, Seo EY, Wearda T, Duldulao C, et al. Identification and characterization of an injury-induced skeletal progenitor. Proc Natl Acad Sci USA. (2015) 112:9920-5. doi: 10.1073/pnas.15130 66112

40. Murphy MP, Koepke LS, Lopez MT, Tong X, Ambrosi TH, Gulati GS, et al. Articular cartilage regeneration by activated skeletal stem cells. Nat Med. (2020) 26:1583-92. doi: 10.1038/s41591-020-1013-2

41. Ortinau LC, Wang H, Lei K, Deveza L, Jeong Y, Hara Y, et al. Identification of functionally distinct Mx1+ $+\mathrm{SMA}+$ periosteal skeletal stem cells. Cell Stem Cell. (2019) 25:784-96.e5. doi: 10.1016/j.stem.2019.11.003

42. Voog J, Jones DL. Stem cells and the niche: a dynamic duo. Cell Stem Cell. (2010) 6:103-15. doi: 10.1016/j.stem.2010.01.011

43. Schofield R. The relationship between the spleen colony-forming cell and the haemopoietic stem cell. Blood Cells. (1978) 4:7-25.

44. Jones DL, Wagers AJ. No place like home: anatomy and function of the stem cell niche. Nat Rev Mol Cell Biol. (2008) 9:11-21. doi: 10.1038/nrm2319 
45. Wagers AJ. The stem cell niche in regenerative medicine. Cell Stem Cell. (2012) 10:362-9. doi: 10.1016/j.stem.2012.02.018

46. Rando TA. Stem cells, ageing and the quest for immortality. Nature. (2006) 441:1080-6. doi: 10.1038/nature04958

47. Josephson AM, Bradaschia-Correa V, Lee S, Leclerc K, Patel KS, Muinos Lopez E, et al. Age-related inflammation triggers skeletal stem/progenitor cell dysfunction. Proc Natl Acad Sci USA. (2019) 116:6995-7004. doi: 10.1073/pnas.1810692116

48. Liu L, Cheung TH, Charville GW, Hurgo BM, Leavitt T, Shih $\mathrm{J}$, et al. Chromatin modifications as determinants of muscle stem cell quiescence and chronological aging. Cell Rep. (2013) 4:189-204. doi: 10.1016/j.celrep.2013.05.043

49. Martin K, Kirkwood TB, Potten CS. Age changes in stem cells of murine small intestinal crypts. Exp Cell Res. (1998) 241:316-23. doi: 10.1006/excr.1998.4001

50. Matsumura H, Mohri $Y$, Binh NT, Morinaga $H$, Fukuda $M$, Ito $\mathrm{M}$, et al. Hair follicle aging is driven by transepidermal elimination of stem cells via COL17A1 proteolysis. Science. (2016) 351:aad4395. doi: 10.1126/science.aad4395

51. Morrison SJ, Spradling AC. Stem cells and niches: mechanisms that promote stem cell maintenance throughout life. Cell. (2008) 132:598611. doi: 10.1016/j.cell.2008.01.038

52. Lin H, Sohn J, Shen H, Langhans MT, Tuan RS. Bone marrow mesenchymal stem cells: aging and tissue engineering applications to enhance bone healing. Biomaterials. (2019) 203:96-110. doi: 10.1016/j.biomaterials.2018.06.026

53. Serowoky MA, Arata CE, Crump JG, Mariani FV. Skeletal stem cells: insights into maintaining and regenerating the skeleton. Development. (2020) 147:179325. doi: 10.1242/dev.179325

54. Tevlin R, Seo EY, Marecic O, McArdle A, Tong X, Zimdahl B, et al. Pharmacological rescue of diabetic skeletal stem cell niches. Sci Transl Med. (2017) 9:aag2809. doi: 10.1126/scitranslmed.aag2809

55. Fazeli PK, Horowitz MC, MacDougald OA, Scheller EL, Rodeheffer MS, Rosen CJ, et al. Marrow fat and bone-new perspectives. J Clin Endocrinol Metab. (2013) 98:935-45. doi: 10.1210/jc.2012-3634

56. Le Y, Fraineau S, Chandran P, Sabloff M, Brand M, Lavoie JR, et al. Adipogenic mesenchymal stromal cells from bone marrow and their hematopoietic supportive role: towards understanding the permissive marrow microenvironment in acute myeloid leukemia. Stem Cell Rev Rep. (2016) 12:235-44. doi: 10.1007/s12015-015-9639-z

57. Ambrosi TH, Scialdone A, Graja A, Gohlke S, Jank AM, Bocian C, et al. Adipocyte accumulation in the bone marrow during obesity and aging impairs stem cell-based hematopoietic and bone regeneration. Cell Stem Cell. (2017) 20:771-84.e6. doi: 10.1016/j.stem.2017.02.009

58. Shore EM, Xu M, Feldman GJ, Fenstermacher DA, Cho TJ, Choi IH, et al. A recurrent mutation in the BMP type I receptor ACVR1 causes inherited and sporadic fibrodysplasia ossificans progressiva. Nat Genet. (2006) 38:5277. doi: $10.1038 / \mathrm{ng} 1783$

59. Kan L, Kessler JA. Evaluation of the cellular origins of heterotopic ossification. Orthopedics. (2014) 37:329-40. doi: 10.3928/01477447-20140430-07

60. Agarwal S, Loder SJ, Sorkin M, Li S, Shrestha S, Zhao B, et al. Analysis of bone-cartilage-stromal progenitor populations in trauma induced and genetic models of heterotopic ossification. Stem Cells. (2016) 34:1692701. doi: 10.1002/stem.2376

61. de Gonzalo-Calvo D, Neitzert K, Fernández M, Vega-Naredo I, Caballero B, García-Macía M, et al. Differential inflammatory responses in aging and disease: TNF- $\alpha$ and IL- 6 as possible biomarkers. Free Radic Biol Med. (2010) 49:733-7. doi: 10.1016/j.freeradbiomed.2010.05.019

62. Ambrosi TH, Goodnough LH, Steininger HM, Hoover MY, Kim E, Koepke LS, et al. Geriatric fragility fractures are associated with a human skeletal stem cell defect. Aging Cell. (2020) 19:e13164. doi: 10.1111/acel.13164

63. Kim HN, Han L, Iyer S, de Cabo R, Zhao H, O'Brien CA, et al. Sirtuin1 suppresses osteoclastogenesis by deacetylating FoxOs. Mol Endocrinol. (2015) 29:1498-509. doi: 10.1210/me.2015-1133

64. Bonkowski MS, Sinclair DA. Slowing ageing by design: the rise of NAD $(+)$ and sirtuin-activating compounds. Nat Rev Mol Cell Biol. (2016) 17:67990. doi: 10.1038/nrm.2016.93

65. Ido Y, Duranton A, Lan F, Weikel KA, Breton L, Ruderman NB. Resveratrol prevents oxidative stress-induced senescence and proliferative dysfunction by activating the AMPK-FOXO3 cascade in cultured primary human keratinocytes. PLoS ONE. (2015) 10:e0115341. doi: 10.1371/journal.pone.0115341

66. Das A, Huang GX, Bonkowski MS, Longchamp A, Li C, Schultz $\mathrm{MB}$, et al. Impairment of an endothelial $\mathrm{NAD}(+)-\mathrm{H}(2) \mathrm{S}$ signaling network is a reversible cause of vascular aging. Cell. (2018) 173:7489.e20. doi: 10.1016/j.cell.2018.02.008

67. Pitak-Arnnop P, Sader R, Dhanuthai K, Masaratana P, Bertolus C, Chaine A, et al. Management of osteoradionecrosis of the jaws: an analysis of evidence. Eur J Surg Oncol. (2008) 34:1123-34. doi: 10.1016/j.ejso.2008.03.014

68. McCaul JA. Pharmacologic modalities in the treatment of osteoradionecrosis of the jaw. Oral Maxillofac Surg Clin North Am. (2014) 26:24752. doi: 10.1016/j.coms.2014.02.002

69. Dalinka TM, Haygood MK. Radiation changes. Philadelphia, PA: Saunders. (1995).

70. Galloway JL, Delgado I, Ros MA, Tabin CJ. A reevaluation of X-irradiationinduced phocomelia and proximodistal limb patterning. Nature. (2009) 460:400-4. doi: 10.1038/nature08117

71. Chandra A, Lin T, Young T, Tong W, Ma X, Tseng WJ, et al. Suppression of sclerostin alleviates radiation-induced bone loss by protecting bone-forming cells and their progenitors through distinct mechanisms. J Bone Miner Res. (2017) 32:360-72. doi: 10.1002/jbmr.2996

72. Li C, Ominsky MS, Tan HL, Barrero M, Niu QT, Asuncion FJ, et al. Increased callus mass and enhanced strength during fracture healing in mice lacking the sclerostin gene. Bone. (2011) 49:1178-85. doi: 10.1016/j.bone.2011.08.012

73. Li X, Niu QT, Warmington KS, Asuncion FJ, Dwyer D, Grisanti M, et al. Progressive increases in bone mass and bone strength in an ovariectomized rat model of osteoporosis after 26 weeks of treatment with a sclerostin antibody. Endocrinology. (2014) 155:4785-97. doi: 10.1210/en.2013-1905

74. Li X, Ominsky MS, Niu QT, Sun N, Daugherty B, D'Agostin D, et al. Targeted deletion of the sclerostin gene in mice results in increased bone formation and bone strength. J Bone Miner Res. (2008) 23:860-9. doi: 10.1359/jbmr. 080216

75. Adam RC, Yang H, Rockowitz S, Larsen SB, Nikolova M, Oristian DS, et al. Pioneer factors govern super-enhancer dynamics in stem cell plasticity and lineage choice. Nature. (2015) 521:366-70. doi: 10.1038/nature14289

76. Ge Y, Gomez NC, Adam RC, Nikolova M, Yang H, Verma A, et al. Stem cell lineage infidelity drives wound repair and cancer. Cell. (2017) 169:63650.e14. doi: 10.1016/j.cell.2017.03.042

77. Frechin M, Stoeger T, Daetwyler S, Gehin C, Battich N, Damm EM, et al. Cell-intrinsic adaptation of lipid composition to local crowding drives social behaviour. Nature. (2015) 523:88-91. doi: 10.1038/nature14429

78. Ilizarov GA. The tension-stress effect on the genesis and growth of tissues. Part I. The influence of stability of fixation and soft-tissue preservation. Clin Orthop Relat Res. (1989) 38:249-81. doi: 10.1097/00003086-198901000-00038

79. McCarthy JG, Stelnicki EJ, Mehrara BJ, Longaker MT. Distraction osteogenesis of the craniofacial skeleton. Plast Reconstr Surg. (2001) 107:181227. doi: 10.1097/00006534-200106000-00029

80. Aljerian A, Gilardino MS. Treacher collins syndrome. Clin Plast Surg. (2019) 46:197-205. doi: 10.1016/j.cps.2018.11.005

81. Hong $\mathrm{P}$, McNeil M, Kearns DB, Magit AE. Mandibular distraction osteogenesis in children with Pierre Robin sequence: impact on healthrelated quality of life. Int J Pediatr Otorhinolaryngol. (2012) 76:115963. doi: 10.1016/j.ijporl.2012.04.025

82. Jones RE, Salhotra A, Robertson KS, Ransom RC, Foster DS, Shah HN, et al. Skeletal stem cell-schwann cell circuitry in mandibular repair. Cell Rep. (2019) 28:2757-66.e5. doi: 10.1016/j.celrep.2019.08.021

83. Prasad MS, Charney RM, García-Castro MI. Specification and formation of the neural crest: perspectives on lineage segregation. Genesis. (2019) 57:e23276. doi: $10.1002 /$ dvg. 23276

84. Ransom RC, Carter AC, Salhotra A, Leavitt T, Marecic O, Murphy MP, et al. Mechanoresponsive stem cells acquire neural crest fate in jaw regeneration. Nature. (2018) 563:514-21. doi: 10.1038/s41586-018-0650-9

85. Maruyama T, Jeong J, Sheu TJ, Hsu W. Stem cells of the suture mesenchyme in craniofacial bone development, repair and regeneration. Nat Commun. (2016) 7:10526. doi: $10.1038 /$ ncomms 10526

86. Zhao H, Feng J, Ho TV, Grimes W, Urata M, Chai Y. The suture provides a niche for mesenchymal stem cells of craniofacial bones. Nat Cell Biol. (2015) 17:386-96. doi: 10.1038/ncb3139 
87. Debnath S, Yallowitz AR, McCormick J, Lalani S, Zhang T, Xu R, et al. Discovery of a periosteal stem cell mediating intramembranous bone formation. Nature. (2018) 562:133-9. doi: 10.1038/s41586-0180554-8

88. Di Pietro L, Barba M, Prampolini C, Ceccariglia S, Frassanito P, Vita A, et al. GLI1 and AXIN2 are distinctive markers of human calvarial mesenchymal stromal cells in nonsyndromic craniosynostosis. Int J Mol Sci. (2020) 21:124356. doi: 10.3390/ijms21124356

89. Murphy MK, MacBarb RF, Wong ME, Athanasiou KA. Temporomandibular disorders: a review of etiology, clinical management, and tissue engineering strategies. Int $J$ Oral Maxillofac Implants. (2013) 28:e393-414. doi: 10.11607/jomi.te20

90. Shi J, Lee S, Pan HC, Mohammad A, Lin A, Guo W, et al. Association of condylar bone quality with TMJ osteoarthritis. J Dent Res. (2017) 96:88894. doi: $10.1177 / 0022034517707515$

91. Van Bellinghen $\mathrm{X}$, Idoux-Gillet $\mathrm{Y}$, Pugliano $\mathrm{M}$, Strub $\mathrm{M}$, Bornert F, Clauss F, et al. Temporomandibular joint regenerative medicine. Int $J$ Mol Sci. (2018) 19:20446. doi: 10.3390/ijms19
020446

92. Bianco P, Kuznetsov SA, Riminucci M, Gehron Robey P. Postnatal skeletal stem cells. Methods Enzymol. (2006) 419:11748. doi: 10.1016/S0076-6879(06)19006-0

Conflict of Interest: The authors declare that the research was conducted in the absence of any commercial or financial relationships that could be construed as a potential conflict of interest.

Copyright (C) 2020 Tevlin, Longaker and Wan. This is an open-access article distributed under the terms of the Creative Commons Attribution License (CC BY). The use, distribution or reproduction in other forums is permitted, provided the original author(s) and the copyright owner(s) are credited and that the original publication in this journal is cited, in accordance with accepted academic practice. No use, distribution or reproduction is permitted which does not comply with these terms. 